\title{
Principais elementos de uma teoria da dupla natureza do direito*
}

Robert Alexy**

No centro das minhas reflexões está a tese de que o direito possui uma natureza dupla (Alexy, 2008:292). Ele inclui necessariamente tanto uma dimensão real ou fática, quanto uma ideal ou crítica. O lado fático se reflete nos elementos definitórios da produção formalmente adequada e da eficácia social; o ideal, no da correção moral (Alexy, 2005:29 e segs.). Quem define o direito exclusivamente em função da produção formalmente adequada e da eficácia social defende um conceito de direito positivista. Tão logo se agrega a correção moral como um terceiro elemento necessário, transforma-se o quadro fundamentalmente: forja-se um conceito de direito não positivista. A tese da dupla natureza implica, então, o não positivismo.

A tese da dupla natureza do direito é, como tal, ainda imprecisa e formal. Ela adquire, porém, conteúdo concreto e estrutura clara quando é desdobrada em um sistema. A ideia abrangente desse sistema é a da institucionalização da razão (Alexy, 1999c:23 e segs.). Sua forma política é o constitucionalismo democrático ou discursivo (Alexy, 1998:258 e segs.). O sistema é elaborado em três passos.

\footnotetext{
* Do original Hauptelemente einer Theorie der Doppelnatur des Rechts, publicado em Archiv für Rechts - und Sozialphilosophie, v. 95, n. 2, p. 151-166, abr. 2009b. Tradução de Fernando Leal, mestre em direito público pela Universidade do Estado do Rio de Janeiro (Uerj) e doutorando em direito na ChristianAlbrechts Universität zu Kiel.

** Robert Alexy é professor catedrático de direito público e filosofia do direito da Christian-Albrechts Universität zu Kiel, Alemanha.
} 


\section{Correção e discurso}

\section{A pretensão de correção}

O ponto de partida é a tese de que o direito erige ${ }^{1}$ necessariamente uma pretensão de correção. Para que essa tese se torne mais precisa é necessário responder três perguntas:

Que significa dizer que o direito erige uma pretensão?

Que se entende pelo caráter necessário da pretensão?

Em que consiste o conteúdo da pretensão?

\section{Erigir uma pretensão}

Pretensões podem, de forma rigorosa, ser instituídas apenas por sujeitos aptos a agir e falar (Alexy, 2000b:4). Até o ponto em que o direito é considerado um sistema de normas, ele não pode, como realçou pertinentemente Neil MacCormick (2007:60), erguer nenhuma pretensão. A afirmação de que o direito erige uma pretensão de correção pode, por conseguinte, apenas significar que aqueles que a instituem operam no e para o direito enquanto o criam, interpretam, aplicam e implementam. O legislador e o juiz são casos paradigmáticos. Levantar aquela pretensão significa, primeiro, que por meio dos atos institucionais deles, ou seja, com a aprovação de leis e decisões judiciais, está vinculado o ato não institucional de

\footnotetext{
${ }^{1}$ N. do T. O texto original contém o verbo erheben, cuja tradução mais literal seria "levantar" ou "erguer". Para evitar confusões ou artificialidades na tradução, dá-se preferência aqui ao verbo "erigir", de significado mais amplo em comparação ao "pôr no alto" imediatamente vinculado àquelas possibilidades e, assim, mais próximo ao visado pelo autor no texto original. Sem embargo, outras versões possíveis serão usadas ao longo do artigo (inclusive as mais literais), especialmente para evitar repetições e, assim, facilitar não só a fluidez do texto, como também a compreensão mais adequada do sentido do verbo alemão nos diferentes contextos em que aparece. Essa é, inclusive, a estratégia de que se serviu a tradução inglesa da Teoria da argumentação jurídica (Theorie der Juristischen Argumentation. Die Theorie des Rationalen Diskurses als Theorie der Juristischen Begründung. Frankfurt: Suhrkamp, 1983), elaborada por Ruth Adler e Neil MacCormick (cf. A theory of legal argumentation: the theory of rational discourse as theory of legal justification. Oxford: Oxford University Press, 1989). As traduções para outros idiomas dos textos de Robert Alexy, em grande parte, também não fornecem uma versão consensual para a tradução mais adequada de erheben, já que elas oscilam entre traduções mais literais (como a italiana) e menos literais (como a espanhola, que usa o verbo "suscitar", e a inglesa, que traduz erheben, dependendo do contexto, por to make ou - o que também, em certos momentos, é uma alternativa apropriada - to carry with). As versões em língua portuguesa, por sua vez, servem-se ou do verbo "formular" (Alexy, 2009a:43) que, em certos momentos, parece ajudar pouco a tornar claras as relações existentes entre o direito e a pretensão de correção, ou optam pelo verbo "levantar", ou ainda acompanham simplesmente a tradução inglesa (Alexy, 2001:213, 320 e 323).
} 
“asserção" de que o ato jurídico é correto quanto ao conteúdo e quanto ao procedimento. Correção implica fundamentabilidade. Por isso, a pretensão de correção "assegura", em segundo lugar, a fundamentabilidade (Alexy, 2007b:348 e segs.). ${ }^{2}$ Como terceiro elemento, agrega-se à asserção e ao asseguramento a "expectativa" de que cada um que se coloca sob o enfoque do respectivo sistema jurídico é racional e aceita o ato jurídico como correto. $\mathrm{O}$ ato de erigir uma pretensão de correção se compõe, então, da tríade:

asserção de correção;

garantia de fundamentabilidade;

expectativa de aceitação.

Essa tríade não está vinculada apenas a atos institucionais, como aprovação de leis e decisões judiciais. Todo aquele que, como participante de um sistema jurídico - seja como advogado perante um tribunal, seja como cidadão em uma discussão pública - , apresenta argumentos favoráveis ou contrários a um determinado conteúdo do sistema jurídico, manifesta a pretensão consistente na afirmação da correção, na garantia da fundamentabilidade e na expectativa de aceitação destes.

\section{O caráter necessário}

A pretensão de correção é, pois, significativa para o conceito e para a natureza ${ }^{3}$ do direito apenas quando o direito a traz necessariamente consigo. A necessidade pode ser explicitada e demonstrada por meio de dois exemplos.

No primeiro exemplo está em jogo o primeiro artigo de uma nova Constituição para o estado X, em que a minoria subjuga a maioria. A minoria gostaria de continuar a gozar das vantagens da subjugação da maioria, mas também quer ser franca. A Assembleia Constituinte aprova, por isso, como primeiro artigo da nova Constituição, o seguinte enunciado: "X é uma república soberana, federal e injusta".

Esse artigo constitucional possui algo errado. A pergunta é simplesmente uma: em que consiste o defeito? Sem dúvida, atenta-se contra as convenções sobre a formulação de textos constitucionais. Contudo, isso por si só não esclarece o erro. Um catálogo de direitos fundamentais de 100 páginas que tenta codificar a jurisprudência atual de um tribunal constitucional seria, por exemplo, inusitado

\footnotetext{
2 Em trabalhos anteriores falava-se de uma "garantia" em vez de "asseguramento". Veja Alexy (2000b:6).

${ }^{3}$ Sobre a relação entre conceito e natureza, veja Alexy (2008:290-292, nota 1).
} 
e não convencional ao extremo, mas não teria a pura e simples falta de sentido da cláusula de injustiça. $\mathrm{O}$ mesmo vale para a incorreção moral. Do ponto de vista da moral não haveria qualquer diferença, se a maioria subjugada, em um artigo adicional, fosse privada dos direitos a cuja privação a cláusula de injustiça tem por objetivo. No entanto, sob o ponto de vista da incorreção, haveria, apesar de tudo, uma diferença. A cláusula de injustiça não é apenas imoral, mas também insensata em certo sentido. Eugenio Bulygin (1993:23 e segs.) asseverou que a cláusula de injustiça exprime apenas um erro político, motivo pelo qual ela é considerada por ele "politicamente inapropriada". Isso ela é sem dúvida, embora tal fato também não esclareça completamente o defeito. Muita coisa pode ser politicamente inapropriada em uma Constituição e, nesse sentido, tecnicamente incorreta, sem que isso produza efeitos tão particularmente como o nosso primeiro artigo (Alexy, 2005:66, nota 2). Nem a incorreção convencional, nem a moral, nem a técnica explicam a absurdidade da cláusula de injustiça. Ela resulta, como é comum em absurdos, de uma contradição. Tal contradição que se origina, com o ato constituinte, de uma pretensão de correção que é erigida, a qual, nesse caso, é essencialmente uma pretensão de justiça. ${ }^{4}$ Pretensões incluem, como exposto, asserções. No caso da pretensão de justiça aqui levantada, a asserção é a de que a república é justa. A contradição consiste então na assertiva de que, com o ato constituinte, é implicitamente sustentada uma afirmação que contradiz o conteúdo explícito ${ }^{5}$ do ato constituinte: a cláusula de injustiça.

O segundo exemplo trata de um juiz que prolata a seguinte sentença: "O acusado é condenado à prisão perpétua, o que é uma falsa interpretação do direito vigente".

A frase dá margem a uma série de questões que não devem, porém, ser enfrentadas. ${ }^{6}$ Nesse contexto somente é relevante que a suposição de um erro convencional, moral ou técnico, assim como a suposição de uma violação do direito positivo (Alexy, 2005:69, nota 2), não sejam também suficientes para captar o caráter particular da incorreção. A absurdidade da sentença se esclarece nesse caso também por uma contradição. Através uma decisão judicial é erguida a pretensão de que o direito é aplicado corretamente, ainda que essa pretensão também seja pouco satisfeita. A pretensão de correção erigida com a consumação do ato institucional de condenação contradiz como falsa a classificação da decisão deste. Instituir uma pretensão de correção significa, entre outras coisas, asseverar implicitamente que a

\footnotetext{
${ }^{4}$ Justiça não é mais do que um caso especial de correção, a saber, correção em relação à distribuição e à equiparação. Cf. Alexy (1997b:105).

${ }^{5}$ Para maiores detalhes sobre o assunto, Alexy (2000a:140).

${ }^{6}$ Cf. sobre o assunto, de um lado, Neumann (1986:87-89), assim como Bulygin (1993:23, nota 9) e, de outro lado, Alexy (1997a:247-249).
} 
decisão é correta. Essa asserção implícita é contraditória com a afirmação explícita e pública vinculada à decisão de que esta é falsa. Essa contradição entre o implícito e o explícito esclarece a absurdidade.

Poderia ser objetado que tudo isso ainda não evidencia a necessidade da pretensão de correção. A absurdidade seria evitável em ambos os casos. Seria preciso apenas mudar fundamentalmente a prática e a autocompreensão atuais do direito. Constituições seriam, desde o início, interpretadas exclusivamente por todos como expressões de poder, vontade, força e decisões judiciais como uma mistura de comando, decisão e emoção. Ambas seriam, assim, naturalisticamente entendidas e, ao mesmo tempo, também se dissipariam dos nossos exemplos sobre a pretensão de correção a contradição e, com isso, a absurdidade. A pretensão de correção seria substituída por algo como uma pretensão de poder. Essa possibilidade de substituição do direito por puro poder mostra em que sentido a pretensão de correção é necessária. Ela é necessária relativamente a uma práxis definida essencialmente por meio da distinção entre verdadeiro e falso, ou seja, por meio da normatividade. Essa práxis é, no entanto, uma prática de tipo especial. Podemos, por certo, tentar nos despedir das categorias da correção, da fundamentabilidade e da objetividade, seja totalmente, seja pelo menos no âmbito da coordenação e da cooperação sociais. ${ }^{7}$ Se isso funcionasse, nossos discursos e ação seriam essencialmente diferentes do que são agora. O preço para tanto seria alto. Ele consistiria, em certo sentido, em nós mesmos. Nessa medida, a fundamentação da necessidade da pretensão de correção - se ela quer ser mais do que a explicação de uma prática faticamente existente - opera em uma dimensão existencial (Alexy, 2004:21).

\section{O conteúdo}

Com a tese de que uma pretensão de correção é erigida, nada é dito a respeito do seu conteúdo. Isso depende do contexto institucional. Valem, assim, para uma assembleia constituinte critérios diferentes dos que valem para as decisões judiciais. Duas questões distintas caracterizam, contudo, a pretensão de correção do direito em todos os contextos: ela compreende, em primeiro lugar, sempre uma

\footnotetext{
${ }^{7}$ Raz asseverou que o argumento da correção não é mais do que uma "tese geral sobre ações intencionais e seus produtos", de sorte que ele também é correto para a ação de bandidos. Ele adota, nesse caso, a forma de uma pretensão de que o que é feito pelos bandidos é relativamente apropriado aos seus objetivos, o que pode significar que a ação é "autoenriquecedora" (Raz, 2007:27). Contra isso se diz que a pretensão de correção, como exposto, engloba um asseguramento de fundamentabilidade e uma expectativa de aceitação por todos. Com isso, não é compatível o objetivo de autoenriquecimento ilícito. A pretensão de Raz à adequação dos propósitos não atinge a dimensão de objetividade contida na pretensão de correção (Alexy, 2007a:49).
} 
pretensão de fundamentabilidade e, em segundo lugar, ela se refere sempre, como ainda será exposto, ao menos também à simples correção moral. Dessa forma não apenas é asseverado - com uma decisão de um tribunal - que o direito posto e eficaz é observado, como também ele mesmo e sua interpretação são corretos.

\section{Teoria do discurso}

Poderia ser objetado que a pretensão de correção, à medida que ela remete à moral, seria apenas expressão de uma ilusão. Julgamentos sobre o que é moralmente obrigatório, proibido e permitido, bom e mau, justo e injusto seriam subjetivos, relativos e resultados de puras decisões. Questões práticas não seriam (excluídas as de maximização de utilidade) racionalmente solucionáveis. Confronto essa objeção de irracionalismo com a teoria do discurso.

\section{As ideias fundamentais da teoria do discurso}

A teoria do discurso é uma teoria procedimental da verdade ou da correção prática (Alexy, 1995a:94 e segs.). ${ }^{8}$ A tese principal de todas as teorias procedimentais da correção prática é a de que a correção de uma asserção normativa depende da possibilidade de a asserção ser ou poder ser o resultado de um procedimento determinado. É uma propriedade essencial da teoria do discurso que esse procedimento não é de negociação, nem de decisão, mas sim de argumentação.

O procedimento do discurso é definido por meio de um sistema de regras discursivas, ${ }^{9}$ que exteriorizam as condições do argumentar prático racional. Uma parte dessas regras, cuja validade é também independente da teoria do discurso, formula exigências gerais de racionalidade. A esse grupo pertencem a ausência de contradição, a possibilidade de universalização - no sentido do emprego consistente dos predicados utilizados - , a clareza linguístico-conceitual, a verdade empírica, a consideração das consequências, o ato de ponderar, a troca de papéis e a análise da formação dos convencimentos morais. Todas essas regras também valem para monólogos. Isso já deixa claro que a teoria do discurso, ao contrário do que foi objetado contra ela (Weinberger, 1994:258 e segs.), de jeito algum substitui a fundamentação pela mera produção de consensos. Ela inclui integralmente

\footnotetext{
${ }^{8}$ Uma análise abrangente da teoria do discurso do direito em confronto com as suas críticas encontra-se em Carsten Bäcker (2008).

${ }_{9}^{9}$ Para formular tal sistema com a ajuda de 28 regras de discurso, cf. Robert Alexy (1996b:234-255).
} 
as regras do argumentar racional aplicáveis a fundamentações monológicas. Sua particularidade consiste exclusivamente na adição a esse nível de um segundo, a saber, o nível das regras relativas ao procedimento do discurso. Essas regras possuem caráter não monológico. Seu objetivo é a imparcialidade do discurso. Esse objetivo deve ser alcançado por meio da garantia da liberdade e da igualdade da argumentação. As mais importantes dessas regras são:

Qualquer um apto a falar pode participar de discursos.

a) Qualquer um pode questionar qualquer alegação; b) qualquer um pode introduzir qualquer alegação no discurso; c) qualquer um pode expressar seus pontos de vista, desejos e necessidades.

Nenhum falante pode ser privado de exercer os direitos estipulados nos dois itens anteriores por meio de coerção dominante dentro ou fora do discurso (Alexy, 1996b:240, nota 18).

Essas regras exteriorizam as ideias de liberdade e igualdade no plano da argumentação. Se elas são válidas, ou seja, qualquer um pode decidir livre e igualmente sobre o que aceita, então vale necessariamente a seguinte condição de aprovação universal: "Uma norma só pode encontrar aprovação universal em um discurso se as consequências de sua observância geral para a satisfação dos interesses de cada um dos indivíduos podem ser aceitas por todos".

São suposições centrais da teoria do discurso que a aprovação discursiva pode depender, em primeiro lugar, de argumentos e que, em segundo lugar, existe uma relação necessária entre a aprovação universal sob condições ideais e os conceitos de correção e, dessa maneira, de validade moral. Essa conexão é formulada da seguinte forma: "Corretas e, assim, válidas são precisamente as normas que seriam qualificadas como corretas por qualquer um em um discurso ideal".

\section{Os limites da teoria do discurso}

A teoria do discurso traz inúmeros problemas. Três deles são especialmente significativos. O primeiro trata da teoria do discurso como teoria da correção prática. Ele pode ser descrito como o "problema do status". O problema do status se refere à existência de fato de uma relação necessária, como afirma a teoria do discurso, entre discursos e correção prática. ${ }^{10} \mathrm{O}$ segundo problema diz respeito à fundamentação das regras do discurso. $\mathrm{O}$ "problema da fundamentação" é re-

\footnotetext{
${ }^{10}$ Cf., sobre o assunto, Alexy (1995c:118-123) e Alexy (2007b:347 e segs., nota 7).
} 
solvido se for possível mostrar que, primeiro, aqueles que participam da prática de afirmar, perguntar e argumentar pressupõem necessariamente essas regras e, segundo, que a participação em tal prática é necessária para qualquer um em qualquer sentido. Tentei demonstrar que tanto este como aquele são corretos (Alexy, 1995b:132-144). Aqui deve ficar em primeiro plano o terceiro problema: o "problema da aplicação" da teoria do discurso.

Do ponto de vista da aplicabilidade, a principal fraqueza da teoria do discurso consiste em que seu sistema de regras não oferece nenhum procedimento que permita, em um número finito de operações, alcançar sempre e exatamente um único resultado. Há três razões para tanto. A primeira, as regras do discurso não contêm qualquer determinação a respeito dos pontos de partida do procedimento. Os pontos de partida são, dependendo do caso, as crenças normativas existentes ou as interpretações dos interesses dos participantes. A segunda, as regras do discurso não determinam todos os passos da argumentação. A terceira razão, uma série de regras do discurso possui caráter ideal, sendo essas regras, por isso, realizáveis apenas de modo aproximado.

$\mathrm{O}$ último ponto conduz à distinção fundamental para a teoria do discurso entre discursos ideais e reais. O discurso prático ideal em todos os aspectos é definido pela busca de uma resposta para uma questão prática sob as condições de tempo ilimitado, participação ilimitada e completa ausência de coerção na direção da produção de completa clareza linguístico-conceitual, completa informação empírica, completa capacidade e disposição para a troca de papéis e completa imparcialidade. O conceito de discurso ideal provoca uma série de problemas (Alexy, 1995c:113-123, nota 21) e é objeto de severas críticas (Weinberger, 1994:259-262, nota 19). Nunca um homem participou de um discurso ideal em todos os aspectos e nunca um mortal o fará. Acerca dos resultados de discursos ideais não pode, por isso, jamais haver certeza, mas sempre - e tão somente - meras suposições. Além disso, nem sequer pode haver certeza sobre a possibilidade de um discurso ideal em todos os aspectos levar a um consenso em cada questão prática ou sobre a existência de uma diversidade de pessoas resistentes ao discurso que também excluiriam consensos sob as condições mais ideais.

Tudo isso não é, porém, capaz de desqualificar o conceito de discurso ideal. A suposição de um discurso ideal é uma simples ideia regulativa ${ }^{11}$ sempre presente em discursos reais. Como ideia regulativa, aquele expressa os objetivos ou pontos finais deste. Discursos práticos reais são definidos pela busca, em seu âmbito, de uma resposta para questões práticas sob as condições de tempo limitado, participação limitada e limitada ausência de coerção com limitada clareza linguístico-

\footnotetext{
${ }^{11}$ Sobre o conceito de ideia regulativa, cf. Immanuel Kant (1974:644-672).
} 
conceitual, informação empírica limitada, capacidade limitada para o câmbio de papéis e imparcialidade limitada. Apesar dessas limitações, o discurso real se encontra necessariamente vinculado com o ideal. Quem tenta convencer um oponente com argumentos, pressupõe que este deveria consentir sob condições ideais. $\mathrm{O}$ discurso ideal como ideia regulativa e a pretensão de correção são, dessa maneira, dois lados de uma mesma coisa.

Contra isso poderia ser objetado que o discurso ideal como ideia regulativa seria algo desprovido de sentido. Seria assim se uma aproximação dele fosse ou impossível, ou irrelevante para a correção. É fácil reconhecer a possibilidade de uma aproximação entre discursos reais e ideais. Há, dessa forma, discursos limitados e abertos, obscuros e claros, autoritários e críticos, e tudo isso (e muito mais) existe em diferentes graus. A questão, portanto, pode apenas dizer respeito à existência de uma conexão interna entre a aproximação de discursos ideais e a correção prática. Há bons motivos para que esse seja o caso. Os discursos práticos não se voltam apenas para a apuração dos interesses gerais, mas também essencialmente à correta solução de conflitos de interesses. Uma solução correta de conflitos de interesses é, no fundo, uma questão de correta determinação dos pesos relativos dos interesses em jogo. Suponha-se apenas que uma norma $N_{1}$ solucionadora de um conflito de interesses encontre aceitação geral após um discurso do qual foram excluídos oponentes não dispostos ao acordo e no âmbito do qual um grupo dominou, uma retórica emocional reinou sobre o ambiente, fatos falsos foram tratados como verdadeiros até o fim e os vencedores consideraram exclusivamente os seus próprios interesses e não quiseram ouvir os dos outros. Compare-se esse cenário com a solução do mesmo conflito de interesses pela norma $N_{2}$, que encontrou aceitação geral após um discurso do qual ninguém foi excluído e no âmbito do qual ninguém dominou (argumentou-se clara e precisamente), apenas suposições sobre relações factuais corretas ou prováveis foram feitas e todos, tanto quanto possível, colocaram-se na situação dos outros e, com base nisso, trataram da interpretação dos seus interesses. O segundo caso está indubitavelmente mais próximo do discurso ideal do que o primeiro e tudo leva a crer que $N_{2^{\prime}}$ ainda que ceteris paribus, está mais próximo da correção do que $N_{1}$. Isso é suficiente para o que está em pauta aqui: a aproximação dos discursos reais dos ideais não é irrelevante para a correção.

A conexão do discurso real com o ideal é capaz de eliminar a indefinição de resultados apenas de modo altamente limitado. Há certas coisas que não são levadas em consideração como resultado por causa da sua aproximação - suficiente e, no geral, também possível na prática - do discurso ideal. A escravidão é um exemplo. Ela pode ser caracterizada como "discursivamente impossível" (Alexy, 1996b:256, nota 18). Outros casos podem, com suficiente segurança, ser classificados como resultados discursivos e devem, portanto, ser considerados "discursi- 
vamente necessários". Os direitos humanos e a democracia são exemplos (Alexy, 1995b:148 e segs., nota 22). Em inúmeros casos, contudo, podem ser defendidas concepções inconciliáveis ao final de um discurso, sem que isso atente contra as suas regras. As visões concorrentes, em razão da sua compatibilidade com as regras do discurso, podem ser caracterizadas como "discursivamente possíveis". Mas desacordo discursivamente possível é desacordo racional. A teoria do discurso esbarra aqui em um limite que ela não consegue superar por si só. Isso pode ser chamado de o "problema do conhecimento".

\section{Positividade}

O problema do conhecimento obriga deixar de lado o primeiro nível, que é definido somente pelos ideais da correção e do discurso, e passar para um segundo nível, no qual procedimentos regrados jurídico-positivamente garantem a produção de decisões, como no caso de votações parlamentares. Esse é o passo para a positividade definida por meio da produção do direito.

O problema do conhecimento não é o único que conduz da pura teoria do discurso para o direito positivo. Outros dois logo se agregam: os problemas da implementação e da organização. O problema da implementação surge porque o simples conhecimento da correção de uma norma não garante a sua observância. Contudo, se alguns podem violar uma norma sem risco, sua observância não pode mais ser exigida de ninguém. Isso leva à necessidade da vinculação entre direito e coerção como um elemento decisivo da eficácia social (Alexy, 2008:292, nota 1). O problema da organização, por fim, resulta da impossibilidade de alcance ou realização satisfatória de inúmeras exigências morais e objetivos valorosos apenas por meio da ação individual ou da cooperação espontânea. A segurança social é um exemplo cuja organização pressupõe o direito. Isso vale para a própria administração do direito. O direito deve ser organizado pelo direito. A tese da dupla natureza conduz assim, em primeiro lugar, à idealidade na forma de correção e discurso e, então, à facticidade na forma de positivação e eficácia.

\section{Institucionalização da razão}

Poder-se-ia pensar que, com a transição do discurso para a facticidade da positivação e da eficácia, ter-se-ia dado o passo para o positivismo jurídico (Braun, 1988:259 e segs.). Mas isso seria uma má interpretação da tese da dupla natureza. De acordo com a tese da natureza dupla, o direito possui necessariamente tanto uma dimensão fática ou real, quanto uma ideal ou crítica. $\mathrm{O}$ caráter necessário 
dessa conexão decorre de dois princípios contrapostos: o da segurança jurídica e o da justiça. Já que a pretensão de correção envolve ambos os princípios (Alexy, 2008:293, nota 1), estão os dois necessariamente vinculados com o direito. O princípio da segurança jurídica exige a vinculação às leis formalmente corretas e socialmente eficazes; o da justiça reclama a correção moral das decisões. Nenhum dos dois princípios pode jamais sobrepujar o outro totalmente. A tese da natureza dupla exige a colocação de ambos os princípios na relação correta. No que se refere a essa relação, ela diz respeito à correção em um sentido abrangente de facticidade e idealidade. Nesse caso, pode-se falar também de uma "correção de segunda ordem". A produção dessa correção de segunda ordem é tarefa do terceiro passo, que diz respeito à institucionalização da razão.

\section{O limite extremo}

A institucionalização da razão é um empreendimento complexo. Quatro aspectos são diferenciados. O primeiro é o do limite máximo do direito. Nesse caso, trata-se de rechaçar a famosa frase de Hans Kelsen (1960:201): "[por] conseguinte qualquer conteúdo arbitrário pode ser direito". O que pode, nesse sentido, ser direito, ilustra Kelsen com a seguinte observação: "[de] acordo com o direito de estados totalitários, o governo está autorizado a prender pessoas de convicção, religião ou raça indesejáveis em campos de concentração, obrigá-las a qualquer trabalho e, sim, matá-las" (Kelsen, 1960:42). Contra isso há de ser oposta a fórmula de Radbruch (1990:89), passível de ser apresentada na forma concisa (Alexy, 1999a:15 e segs.): "injustiça extrema não é direito".

O especial nessa fórmula é que ela vincula direito e moral sem exigir uma completa convergência entre ambos. Ela permite, assim, que o direito positivo também seja válido mesmo quando injusto. ${ }^{12}$ Normas postas em conformidade formal e socialmente eficazes perdem seu caráter de direito ou sua validade jurídica apenas quando as barreiras da injustiça extrema são transpassadas.

A pretensão de correção integra, de fato, uma importante base da fórmula de Radbruch, mas ela, tomada individualmente, não é suficiente para fundamentá-la. Para tanto, são necessárias outras razões. Entre estas, razões normativas desempenham um papel especial. Isso já foi objeto de exposição detalhada (Alexy, 2005:52108, nota 2). Por isso, esse ponto deve tratar apenas da pergunta fundamental a respeito da possibilidade de fundamentos normativos desempenharem um papel

\footnotetext{
${ }^{12}$ Com o foco nessa fórmula pode-se, por conseguinte, falar em um "não positivismo inclusivo". Cf. Alexy (2008:286-290, nota 1).
} 
fundamental para a determinação do conceito e da natureza do direito, como, em geral, os princípios da segurança jurídica e da justiça mencionados supra.

Joseph Raz (1996:7) aduziu que a pergunta a respeito da natureza do direito é uma questão teórica, e não prática ou normativa, e que a teoria deve exclusivamente constatar "como as coisas $s \tilde{a} o^{\prime} .{ }^{13}$ A pergunta sobre a possibilidade de a fórmula de Radbruch dizer algo correto sobre a natureza do direito ou - como concebe Raz - de uma regra ser válida, "dado aos tribunais o poder para desconsiderar leis grosseiramente injustas", diria respeito, por isso, "a uma questão de fato social" (Raz, 2007:31, nota 15). Mas eu deveria ter mostrado a existência necessária de um tal fato social em todos os sistemas jurídicos (Raz, 2007:31, nota 15). Contra isso há de se opor que a fórmula de Radbruch não descreve nenhum fato social. Na verdade, ela é a contrapartida de um fato social. Ela coloca limites à validade jurídica fundada nos fatos sociais da produção do direito formalmente adequada e da eficácia fática.

Permanece, certamente, a pergunta sobre a possibilidade de ela fazer isso com base em fundamentos morais, ou seja, normativos. Isso foi contestado com especial ênfase por Andrei Marmor (2005:778): “[uma] vez que admitimos que, para obter algo como a fórmula de Radbruch, é preciso um argumento normativo, conta-se com um argumento moral para nos dizer algo sobre o direito. Não é mais o caso que a conclusão diz respeito à natureza do direito. Tão simples quanto isso".

Deve ser impugnado que seja realmente tão simples. Não é tão simples porque, ao lado da perspectiva do observador, há a perspectiva do participante (Alexy, 2005:47 e segs., nota 2) e porque esta última é necessária para o direito, ou seja, pertence à sua natureza. Sem participante não há direito. A diferença entre as duas perspectivas consiste em que o observador inquire sobre como se decide de fato em um determinado sistema jurídico, enquanto o participante inquire sobre qual é a resposta correta para uma questão jurídica em um determinado sistema jurídico. Para o observador, o direito consiste exclusivamente naquilo que realmente foi posto e é socialmente eficaz. ${ }^{14}$ Isso é, de fato, como se refere Raz, "uma questão de fato social”. Ao contrário, na perspectiva do participante, a resposta para a pergunta sobre o que é válido como direito e, nesse sentido, é direito, depende do que pode ser corretamente afirmado como direito. A correção de uma afirmação sobre o que é o direito, no entanto, não depende somente de fatos sociais, mas também de argumentos morais. Nesse

\footnotetext{
${ }^{13}$ Grifo nosso.

${ }^{14}$ Isso não exclui as considerações das reflexões dos observadores sobre como o direito, na opinião dos participantes, deva ser. Pode-se falar, no caso, de considerações indiretas ou em "terceira pessoa" sobre como o direito deve ser. Os participantes, ao contrário, realizam considerações diretas ou em primeira pessoa.
} 
sentido, argumentos morais pertencem às condições de correção das afirmações jurídicas. ${ }^{15}$ Com isso, o que o direito deve ser encontra entrada naquilo que o direito é. $\mathrm{O}$ "é" do participante é, dessa forma, necessariamente um "é" que inclui um dever-ser. Assim como em relação à correção poder-se-ia também falar de um "'ser' de segunda ordem". ${ }^{16}$

\section{Constitucionalismo democrático}

A barreira limítrofe de todo o direito é uma condição necessária - de jeito algum uma condição suficiente - da institucionalização da razão. Não se trata, por conseguinte, de apenas resolver a confrontação entre positividade e correção nas bordas, mas também de estabelecer essa conexão nas entranhas até onde isso seja possível. Isso é possível apenas no âmbito da forma política do constitucionalismo democrático ou discursivo.

\section{Direitos Fundamentais}

A teoria do discurso conduz ao constitucionalismo democrático porque ela coloca duas exigências fundamentais para o conteúdo e para a estrutura do sistema jurídico: direitos fundamentais e democracia. Direitos fundamentais são direitos que foram acolhidos no âmbito de uma constituição para positivar direitos humanos (Alexy, 1999b:526). ${ }^{17}$ Direitos humanos são direitos morais de tipo universal, essencial $^{18}$, abstrato e prioritário (Alexy, 2004:16, nota 16). Como tentativa de positivação de direitos morais, os direitos fundamentais exteriorizam de forma especialmente significativa a natureza dupla do direito.

Os direitos humanos podem, é certo, colocar exigências para o sistema jurídico apenas se existirem. Eles existem quando são válidos. Sem embargo, a validade

\footnotetext{
${ }^{15}$ Cf. Ronald Dworkin (2006:2), que em vez de "condições de correção", fala em "condições de verda$\mathrm{de}^{\prime \prime}$ (truth conditions).

${ }^{16}$ N. do T. No original lê-se "é de segunda ordem" (Ist zweiter Stufe). Optamos, contudo, por usar neste caso específico, o infinitivo do verbo "ser" e colocá-lo entre aspas para facilitar a compreensão da passagem.

${ }^{17} \mathrm{~N}$. do T. Aqui e no restante do texto, a expressão "direitos humanos" não deve ser reduzida à categoria dogmática dos direitos reconhecidos na esfera internacional, mas sim entendida em um sentido mais amplo, de forma a abranger, especialmente, os direitos inerentes à própria condição humana.

${ }^{18}$ N. do T. No original, o autor usa "fundamentaler [...] Art", expressão neste ponto traduzida por "de tipo essencial", a despeito da adequação da tradução mais literal ("de tipo fundamental"), para evitar confusões entre a afirmação do caráter "fundamental" dos direitos humanos e os "direitos fundamentais" (Grundrechte).
} 
dos direitos humanos como direitos morais depende da possibilidade de fundamentá-los - e de nada mais.

Tentei há algum tempo fundamentar discursivo-teoricamente os direitos humanos a partir de um argumento transcendental (Alexy, 1995b:132 e segs., nota 22). É possível qualificar esse ponto de partida também como "explicativo" (Alexy, 2004:19 e segs., nota 16). O argumento explicativo consiste em uma análise da práxis discursiva, que é uma práxis caracterizada pelo afirmar, questionar e aduzir de razões. Essa práxis pressupõe necessariamente regras que expressam as ideias de liberdade e igualdade dos participantes do discurso (Alexy, 1995b:132-142, nota 22). Liberdade e igualdade no discurso não implicam ainda, por certo, liberdade e igualdade no agir. Para dar esse passo é preciso agregar às faculdades discursivas um interesse no uso destas na ação. Esse interesse pode ser chamado de "interesse na correção". Essa ligação entre faculdade e interesse implica o reconhecimento do outro como autônomo (Alexy, 1995b:148-151). Quem reconhece o outro como autônomo, reconhece-o como pessoa. Quem o reconhece como pessoa, atribui-lhe dignidade. Quem lhe atribui dignidade, reconhece seus direitos humanos. Com isso, estamos no centro da fundamentação.

Poder-se-ia objetar que isso não é nenhuma fundamentação. Na verdade, a explicação da pressuposição necessária de uma práxis pode ser considerada como fundamentação quando se classifica essa práxis como necessária. Este último é, todavia, o caso, à medida que, em se tratando da práxis de afirmar, questionar, fornecer e obter razões, aquele que durante toda a sua vida não faz nenhuma afirmação, não formula qualquer pergunta, não aduz nenhum argumento e não participa daquilo que se poderia chamar de "a forma mais geral de vida do ser humano" (Alexy, 1995b:139). O argumento em favor da fundamentação dos direitos humanos deixaria, no entanto, de ser um fundamento tão logo interesses entrassem em jogo.

Essa objeção tem algo de correto. Mas ela deve ser relativizada. O interesse na correção está, como qualquer interesse, vinculado na verdade com decisões sobre a possibilidade de ele prevalecer em face de interesses concorrentes. Essa questão, no entanto, diz respeito à questão fundamental sobre a aceitação por nós mesmos das nossas possibilidades discursivas. Ela diz respeito à possibilidade de nos desejarmos como, no dizer de Brandom (2000:26), criaturas discursivas. Isso é uma decisão sobre quem somos. Esse passo de fundamentação pode ser chamado de "existencial". Pode-se falar, no caso, de uma "fundamentação" porque não se trata de encontrar quaisquer preferências a partir de nenhum lugar ou de um lugar qualquer, mas sim da comprovação de algo - já no caminho da explicação enquanto possibilidade - necessariamente comprovado (Alexy, 2004:21, nota 16). 


\section{Democracia}

A segunda exigência é a democracia. Há concepções de democracia extremamente diferentes. O princípio do discurso reclama a democracia deliberativa. A democracia deliberativa é mais do que um procedimento para a produção de um acordo de interesses sob a sombra de ditadura ou de guerra civil. Nela, o plano dos interesses e do poder é superposto pelo plano dos argumentos, no qual todos os interessados debatem sobre uma solução política correta. A democracia deliberativa pressupõe, dessa forma, a possibilidade da racionalidade discursiva. Fosse a racionalidade discursiva impossível, seria a democracia deliberativa uma ilusão.

O fato de a possibilidade da democracia deliberativa depender da possibilidade de discursos práticos racionais é apenas um lado da questão. O outro é que a ideia do discurso somente pode ser realizada tanto quanto ela é realizável por meio da institucionalização da democracia deliberativa. Quem deseja correção, deve desejar discursos; quem deseja discursos, deve desejar a democracia (Alexy, 1996a:354).

\section{Jurisdição constitucional}

Se o processo de formação da vontade política tem êxito, a maioria parlamentar respeitará e concretizará tanto os direitos fundamentais quanto também as regras da democracia deliberativa. O que acontece, porém, quando leis violadoras de direitos fundamentais ou incompatíveis com os princípios da democracia são promulgadas? Pode-se ou confiar na força autocurativa da democracia deliberativa, ou estabelecer uma jurisdição constitucional. A última opção merece prioridade. ${ }^{19}$ Cada jurisdição constitucional, por certo, encerra o perigo de um paternalismo incompatível com a ideia de autodeterminação democrática (Habermas, 1994:323). Mas ele pode ser impedido se a jurisdição constitucional é conceituada como representação argumentativa dos cidadãos e tem êxito (Alexy, 2006:255-258). Isso torna claro que o constitucionalismo democrático é possível apenas como constitucionalismo discursivo (Alexy, 2006:250).

\section{Argumentação jurídica}

Nenhum legislador pode criar um sistema de normas tão perfeito em que cada caso pode ser solucionado apenas a partir de uma simples subsunção da

\footnotetext{
${ }^{19}$ Alexy (1998:262-264, nota 4) e Alexy (1999c:37 e segs., nota 3).
} 
descrição das circunstâncias à hipótese de incidência de uma regra. Para tanto, há vários motivos. Os mais significativos são a vagueza da linguagem do direito, a possibilidade de conflitos normativos, a ausência de normas nas quais a decisão pode se sustentar e a possibilidade, em casos especiais, de também se decidir em sentido contrário ao teor literal de uma norma (Alexy, 1996b:17 e segs., nota 18). Nessa medida existe uma abertura necessária do direito (Hart, 1994:128). Isso é válido, pelo menos em igual medida, também para um sistema de precedentes.

De acordo com a definição, no âmbito da abertura do direito positivo não se pode decidir com base no direito positivo, pois, se isso fosse possível, não se estaria naquele âmbito. Positivistas como Kelsen (1960:350, nota 31) e Hart (1994:126, 135, 204 e segs., nota 59) são, por isso, apenas consequentes quando dizem que o juiz, no âmbito da abertura, está autorizado a decidir, tal qual um legislador, com base em critérios extrajurídicos. A pretensão de correção leva, ao contrário, a uma explicação não positivista, em cujo centro está a tese do caso especial.

A tese do caso especial afirma que o discurso jurídico é um caso especial do discurso prático geral (Alexy, 1996b:263-272, nota 18). A argumentação jurídica, como a argumentação prática geral, trata, no fundo, do que é obrigatório, proibido e permitido, ou seja, de questões práticas. Tanto no discurso prático geral quanto no jurídico é erigida uma pretensão de correção. A peculiaridade consiste no fato de que a pretensão de correção no discurso jurídico não se refere, ao contrário do que ocorre no discurso prático geral, ao que é correto independentemente do direito positivo vigente em cada caso, mas sim ao que é correto no âmbito de um sistema jurídico determinado. O que é correto em um sistema jurídico depende essencialmente do que foi estabelecido autoritativa ou institucionalmente e do que se adapta ao sistema. Se se quer colocar isso em uma fórmula sucinta, pode-se dizer que a argumentação jurídica está vinculada às leis e precedentes, e se deve considerar o sistema de direito desenvolvido pela dogmática jurídica. ${ }^{20}$ Se uma decisão decorre claramente de uma lei, precedente ou construção dogmática e, sob o aspecto da correção interna, não há nenhuma alegação séria, decide-se o caso apenas pelo que foi posto autoritativa e institucionalmente. Mas se as leis precedentes e a dogmática não determinam a resposta para uma questão jurídica - o que define um caso difícil - são necessárias valorações adicionais que não derivam do material autoritativo preestabelecido. Se a pretensão de correção deve cumprir algum papel satisfatório, essas premissas adicionais devem ser fundamentadas. Isso, no entanto, quando o material autoritativo ou institucional por si só não fornece nenhuma resposta, somente é possível na direção da argumentação prática geral.

\footnotetext{
${ }^{20}$ Essas vinculações são expressas por meio das regras e formas específicas do discurso jurídico (Alexy, 1996b:273-367, nota 18).
} 
Habermas (1994:287, nota 55) objetou contra a tese do caso especial que o discurso jurídico não poderia ser concebido como um caso especial do discurso "moral": "Discursos jurídicos [...] não formam nenhum caso especial de argumentação moral". A razão para tanto é que, no direito, argumentos éticos e pragmáticos deveriam desempenhar um papel fundamental ao lado dos argumentos morais (Habermas, 1994:283 e segs.). Como "morais", Habermas qualifica os argumentos relacionados com a justiça (Habermas, 1994:191 e segs.). Questões éticas - nesse caso questões ético-políticas - têm, em contrapartida, por objeto, "autocompreensões coletivas" (Habermas, 1994:139), o que inclui considerações de tradições e valores (Habermas, 1994:139) compartilhados. Por fim, os argumentos pragmáticos dizem respeito a um ajuste de interesses concorrentes no sentido de uma "negociação de compromissos" (Habermas, 1994:139). Tomadas essas diferenciações como base, então Habermas está correto com a sua tese de que o discurso jurídico não é nenhum caso especial do discurso moral, posto que o discurso jurídico está aberto não somente para argumentos morais, como também para argumentos éticos e pragmáticos. Mas isso não atinge a tese do caso especial. Esta não diz que o discurso jurídico é um caso especial do discurso moral, mas, na verdade, que ele é um caso especial do discurso "prático geral". O discurso prático geral é, contudo, um discurso no qual questões práticas são respondidas com razões não autoritativas. Estas abrangem razões tanto morais quanto éticas e pragmáticas. Dessa forma, o discurso prático geral é um discurso no qual concorrem razões morais, éticas e pragmáticas. Essa confluência está relacionada a uma vinculação sistematicamente necessária, que é expressão da unidade substancial da razão prática (Alexy, 1999d:379). A pretensão de correção está relacionada, assim, a todas as três dimensões, entre as quais é atribuída prioridade para as razões morais (Alexy, 2007b:355, nota 7). A tese do caso especial expressa uma conexão necessária entre direito e moral porque afirma que o discurso jurídico compreende o discurso prático geral e este inclui necessariamente o discurso moral.

\section{Teoria dos princípios}

O sistema do constitucionalismo democrático permaneceria incompleto sem a teoria dos princípios. A base da teoria dos princípios é a diferenciação teóriconormativa entre regras e princípios (Alexy, 1996b:75 e segs.). Princípios são mandamentos de otimização. Eles exigem que algo seja realizado na maior medida possível relativamente às possibilidades fáticas e jurídicas. Sua forma de aplicação é a ponderação. Regras são, ao contrário, normas que obrigam, proíbem ou permitem algo definitivamente. Nesse sentido, elas são mandamentos definitivos. Sua forma de aplicação é a subsunção. 
A teoria dos princípios é o sistema de implicações dessa distinção. Essas implicações dizem respeito a todos os âmbitos do direito. Conforme exposto, isso se aplica para o próprio conceito de direito. Nesse domínio, a correta composição entre os princípios da segurança jurídica e da justiça exige que a injustiça extrema não possa ser direito, embora, abaixo desse nível, a injustiça não elimine o caráter de direito ou a validade jurídica. O papel mais importante da teoria dos princípios é desempenhado no âmbito dos direitos fundamentais. $\mathrm{O}$ motivo mais importante para tanto é a relação de implicação recíproca existente entre o caráter de princípio e a máxima da proporcionalidade. A máxima da proporcionalidade e as suas três submáximas da adequação, da necessidade e da proporcionalidade em sentido estrito seguemse logicamente da natureza de princípio e este daquela (Alexy, 1996b:100-104). Isso significa, então, que, se os direitos fundamentais têm a natureza de princípios, a máxima da proporcionalidade é válida e que, se a máxima da proporcionalidade é válida, os direitos fundamentais têm a natureza de princípios.

As submáximas da adequação e da necessidade demandam uma otimização relativa às possibilidades fáticas. Não se trata aqui de ponderação, mas de impedir restrições em direitos fundamentais evitáveis sem custos para outros princípios, ou seja, trata-se de uma otimalidade de Pareto (Alexy, 1996b:149). A máxima da proporcionalidade em sentido estrito diz respeito à otimização relativa às possibilidades jurídicas. As possibilidades jurídicas são determinadas, afora regras, essencialmente por meio de princípios concorrentes. Esse é o campo da ponderação, já que a ponderação consiste em nada mais do que a otimização relativa a princípios concorrentes. A teoria dos princípios é, por isso, uma teoria da ponderação.

Tentei abranger, na "teoria dos direitos fundamentais", compreensivamente a estrutura da ponderação com a ajuda de duas leis: a lei de colisão e a lei de ponderação. Aqui interessa apenas a última. ${ }^{21}$ Ela prescreve o seguinte: “Quanto maior é o grau de não realização ou restrição de um princípio, maior deve ser a importância da realização do outro" (Alexy, 1996b:146).

A lei de ponderação expressa o núcleo de uma estrutura que se pode captar completa e exatamente com a ajuda de uma fórmula. A chamei de "fórmula de sopesamento" (Alexy, 2003:790):

$$
G_{i, j}=\frac{I_{i} \cdot G_{i} \cdot S_{i}}{I_{j} \cdot G_{j} \cdot S_{j}}
$$

" $G_{i, j}$ " representa o peso concreto de um princípio $P_{i}$ relativamente ao princípio colidente $P_{j}$. Se $G_{i, j}$ é maior do que 1 , prevalece $P_{i}$; se $G_{i, j}$ é menor do que 1 , pre-

\footnotetext{
${ }^{21}$ Veja, sobre a lei de colisão, Alexy (1996b:83 e segs.).
} 
valece $P_{j}$. Se $G_{i, j}$ é igual a 1, está-se em xeque, acontece um empate ou estado de igualdade, para cuja solução são necessárias novas considerações. A fórmula de sopesamento define $G_{i, j}$ como o quociente dos produtos de três fatores respectivos. Do lado de $P_{i}$, eles são a intensidade da restrição em $P_{i}\left(I_{i}\right)$, o peso abstrato de $P_{i}\left(G_{i}\right)$ e a segurança das premissas empíricas a respeito do que a implementação da medida sob consideração significa para a não realização de $P_{i}$ $\left(S_{i}\right)$. As contrapartidas para o lado de $P_{j}$ são a intensidade da restrição em $P_{j}$ que se produziria pela não restrição em $P_{i}\left(I_{j}\right)$, o peso abstrato de $P_{j}\left(G_{j}\right)$ e a segurança das premissas empíricas sobre o que a não implementação da medida sob consideração significaria para a realização de $P_{j}\left(S_{j}\right)$.

Esses seis fatores são avaliados com a ajuda de uma escala, como "leve" (l), "médio" $(m)$ e "grave" ( $s)_{,}^{22}$ cujo refinamento é, de fato, completamente possível devido à natureza do direito constitucional, mas encontra rapidamente limites (Alexy, 2003:445). Para calcular o valor de $G_{i, j}$ deve-se atribuir valores a $l, m$ e $s$. Nesse caso, se propõe a progressão geométrica $2^{0}, 2^{1}, 2^{2}$, ou seja, 1,2 e 4 (Alexy 2003:785, nota 76).

Pode-se pensar que, assim, a argumentação é substituída pelo cálculo e que isso não é possível no direito. Esse fato deve ser rebatido, uma vez que números não substituem julgamentos ou proposições, mas simplesmente os representam. Suponha que $P_{i}$ representa o direito fundamental à liberdade de manifestação de pensamento. Se para $I_{i}$ é estabelecido o valor 1, então "1" representa a conclusão, "a restrição na liberdade de manifestação de pensamento é leve". Esse juízo precisa, como qualquer juízo, de justificação por meio de argumentos. Vale aqui o mesmo que vale para as premissas da fórmula de subsunção (Alexy, 2003:448, nota 77). Isso torna claro que a fórmula de sopesamento não é nada mais do que uma forma de argumento (Alexy, 1996b:123, nota 18) do discurso prático. Como forma de argumento, a fórmula de sopesamento não é um concorrente, mas sim um elemento do discurso prático racional. ${ }^{23}$

Dessa maneira, a teoria dos princípios conecta a teoria dos direitos fundamentais e a teoria da argumentação em uma unidade necessária. Adicione-se que, sobre essas bases (é admissível uma teoria das margens de conformação legislativas que permite uma delimitação racional das competências do tribunal constitucional das do Parlamento) (Alexy, 2002:15-30), estão juntos, então, os principais elementos

\footnotetext{
${ }^{22} \mathrm{~N}$. do T. No original, schwer, o que justifica o " $\mathrm{s}$ " usado para designar o fator, letra que, ademais, será mantida nesta versão para evitar as confusões que a tradução por "grave" (ou "pesada") poderia implicar com as outras variáveis da fórmula (especificamente " $\mathrm{g}$ " - usada para peso - e " $\mathrm{p}$ " - usada para princípio).

${ }^{23}$ Vestígios da fórmula de sopesamento se encontram no cânone de regras da "teoria da argumentação jurídica" (nota 9). Cf. p. 249: (4.5), (4.6).
} 
do constitucionalismo democrático. Se o ideal pode ser reconciliado com o real, a institucionalização da razão é uma tentativa de fazê-lo.

\section{Referências}

ALEXY, Robert. Theorie der Juristischen Argumentation. Die Theorie des Rationalen Diskurses als Theorie der Juristischen Begründung. Frankfurt: Suhrkamp, 1983.

. A theory of legal argumentation. The theory of rational discourse as theory of legal justification. Oxford: Oxford University Press, 1989.

. Die Idee einer Prozeduralen Theorie der Juristischen Argumentation. In: ALEXY, Robert. Recht, Vernunft, Diskurs. Frankfurt: Suhrkamp, 1995a.

. Diskurstheorie und Menschenrechte. In: . Recht, Vernunft, Diskurs. Frankfurt: Suhrkamp, 1995b.

. Probleme der Diskurstheorie. In: . Recht, Vernunft, Diskurs. Frankfurt: Suhrkamp, 1995c.

. Grundgesetz und Diskurstheorie. In: BRUGGER, Winfried (Org.). Legitimation des Grundgesetzes aus Sicht von Rechtsphilosphie und Gesellschaftstheorie. Baden-Baden: Nomos, 1996a.

. Theorie der Juristischen Argumentation. Die Theorie des Rationalen Diskurses als Theorie der Juristischen Begründung. 3. ed. Frankfurt: Suhrkamp, 1996b.

. Bulygins Kritik des Richtigkeitsarguments. In: VALDÉS, Ernesto Garzón; KRAWIETZ, Werner; HENRIK von WRIGHT, Georg; ZIMMERLING, Ruth (Orgs.). Normative systems in legal and moral theory. Festschrift for Carlos E. Alchourrón and Eugenio Bulygin. Berlin: Duncker \& Humblot, 1997a.

. Giustizia come correttezza. Ragion Pratica, n. 9, p. 105, 1997 b.

. Die Institutionalisierung der Menschenrechte im Demokratischen Verfassungsstaat. In: GOSEPATH, Stefan; LOHMANN, Georg (Orgs.). Philosophie der Menschenrechte. Frankfurt: Suhrkamp, 1998.

. A defense of radbruch's formula. In: DYZENHAUS, David (Org.). Recrafting the rule of law: The limits of legal order. Oxford: Hart Publishing, 1999a.

. Grundrechte. In: SANDKÜHLER, Hans Jörg (Org.). Enzyklopädie Philosophie. Hamburg: Felix Meiner Verlag, 1999b.

. My philosophy of law: the institutionalization of reason. In: WINTGENS, Luc J. (Org.). The law in philosophical perspectives. Dordrecht: Kluwer, 1999c. 
. The special case thesis. Ratio Juris, n. 12, p. 379, 1999d.

. On the thesis of a necessary connection between law and morality: Bulygin's critique. Ratio Juris, n. 13, p. 140, 2000a.

. Recht und Richtigkeit. In: KRAWIETZ, Werner; SUMMERS, Robert; WEINBERGER, Ota; HENRIK von WRIGHT, Georg (Orgs.). The reasonable as rational? Festschrift for Aulis Aarnio. Berlin: Duncker \& Humblot, 2000b.

. Teoria da argumentação jurídica: a teoria do discurso racional como teoria da justificação jurídica. São Paulo: Landy, 2001.

. Verfassungsrecht und einfaches Recht - Verfassungsgerichtsbarkeit und Fachgerichtsbarkeit. Veröffentlichung der Vereinigung der Deutschen Staatsrechtslehrer, n. 61, p. 15-30, 2002.

. Die Gewichtsformel. In: JICKELI, Joachim; KREUTZ, Peter; REUTER, Dieter (Orgs.). Gedächtnisschrift für Jürgen Sonnenschein. Berlin: The Gruyter, 2003.

. Menschenrechte ohne Metaphysik? Deutsche Zeitschrift für Philosophie, n. 52, p. 21, 2004.

. Begriff und Geltung des Rechts. 4. ed. Freiburg: München, 2005.

. Abwägung, Verfassungsgerichtsbarkeit und Repräsentation. In: BECKER, Michael; ZIMMERLING, Ruth (Orgs.). Politik und Recht. Wiesbaden: VS Verlag, 2006. (Politische Vierteljahresschrift, Sonderheft 36).

An answer to Joseph Raz. In: PAVLAKOS, George (Org.). Law, rights and discourse: the legal philosophy of Robert Alexy. Oxford: Hart Publishing, 2007a.

. Thirteen replies. In: (Org.). Law, rights and discourse: the legal philosophy of Robert Alexy. Oxford: Hart Publishing, 2007b.

. On the concept and the nature of law. Ratio Juris, n. 21, p. 292, 2008.

. Conceito e validade do direito. São Paulo: Martins Fontes, 2009a.

. Hauptelemente einer Theorie der Doppelnatur des Rechts. Archiv für Rechts - und Sozialphilosophie, v. 95, n. 2, p. 151-166, Apr. 2009b.

BÄCKER, Carsten. Begründen und Entscheiden. Kritik und Rekonstruktion der Alexyschen Diskurstheorie des Rechts. Baden-Baden: Nomos, 2008.

BRANDOM, Robert. Articulating reasons. Cambridge/Massachusetts: Harvard University Press, 2000.

BRAUN, Carl. Diskurstheoretische Normenbegründung in der Rechtswissenschaft. Rechtstheorie, n. 19, p. 259 e segs., 1988. 
BULYGIN, Eugenio. Alexy und das Richtigkeitsargument. In: AARNIO, Aulis; PAULSON, Stanley; WEINBERGER, Ota; HENRIK von WRIGHT, Georg; WYDUCKEL, Dieter (Orgs.). Rechtsnorm und Rechtswirklichkeit. Festschrift für Werner Krawietz. Berlin: Duncker \& Humblot, 1993.

DWORKIN, Ronald. Justice in robes. Cambridge/Massachusetts: Harvard University Press, 2006.

HABERMAS, Jürgen. Faktizität und Geltung: Beiträge zur Diskurstheorie des Rechts und des Demokratischen Rechtsstaats. 4. ed. Frankfurt: Suhrkamp, 1994.

HART, H. L. A. The concept of law. 2. ed. Oxford: Oxford University Press, 1994.

KANT, Immanuel. Kritik der reinen Vernunft. Frankfurt: Suhrkamp, 1974.

KELSEN, Hans. Reine Rechtslehre. 2. ed. Wien: Franz Deuticke, 1960.

MAcCORMICK, Neil. Why law makes no claims. In: PAVLAKOS, George (Org.). Law, rights and discourse: the legal philosophy of Robert Alexy. Oxford: Hart Publishing, 2007.

MARMOR, Andrei. Debate. Anales de La Cátedra Francisco Suárez, n. 39, p. 778, 2005.

NEUMANN, Ulfrid. Juristische Argumentationslehre. Darmstadt: Wissenschaftliche Buchgesellschaft, 1986.

RADBRUCH, Gustav. Gesetzliches Unrecht und Übergesetzliches Rechts. [1946]. In: RADBRUCH, Gustav. Gesamtausgabe. Heidelberg: Verlag Lambert, 1990. v. 3.

RAZ, Joseph. On the nature of law. Archiv für Rechts - und Sozialphilosophie, n. 82, p. 7, 1996.

. The argument from justice, or how not to reply to legal positivism. In: PAVLAKOS, George (Org.). Law, rights and discourse: the legal philosophy of Robert Alexy. Oxford: Hart Publishing, 2007.

WEINBERGER, Ota. Grundlagenprobleme des Institutionalistischen Rechtspositivismus und der Gerechtigkeitstheorie. In: KOLLER, Peter; KRAWIETZ, Werner; STRASSER, Peter (Orgs.). Institution und Recht. Berlin: Duncker \& Humblot, 1994. (Rechtstheorie, Beiheft 14). 